\title{
Prospects of High Viscosity Oil Flow Rate in Horizontal Wells
}

\author{
Al-Obaidi SH, Galkin AP, Patkin AA
}

\begin{abstract}
The non-Newtonian nature of fluid flow represents one of the most important features of the development of high-viscosity oil (HVO) deposits. The deviation from the linear law of the fluid flow is associated, first of all, with the formation of a strong spatial structure due to the presence of high-molecular components and dissolved gases in the composition. The stress required to destroy the formed structure is called the shear stress of the ultimate destruction of the structure. In this regard, in order to ensure the flow of HVO through the pore space, it is necessary to create certain values of pressure gradients above the dynamic shear pressure gradient (DSPG). With increasing pressure gradients above the DSPG, the oil structure begins to collapse, and after overcoming the critical value of the pressure gradient of the ultimate destruction of the structure (PGUDS), flow begins to be described by the Newtonian law. The article considers the influence of various factors on the oil flow rate of a horizontal well $(H W)$ that exploits the HVO Deposit. At the same time, numerical experiments were carried out on a hydrodynamic model for the non-Newtonian oil flow regime (in the presence of DSPG) and the results obtained were compared with calculations of the oil flow rate using an analytical formula.
\end{abstract}

Keywords: Flow rate, Pressure gradient, High viscosity oil, SMP, Horizontal wells.

*Author for Correspondence E-mail: drsudad@gmail.com

\section{INTRODUCTION}

Quite a lot of scientific researches are devoted to the peculiarities of the $\mathrm{HVO}$ in a porous medium, the manifestation of non-Newtonian flow. For example, in works [1][2][3] it was established that the presence of heavy components (asphaltenes, paraffins, resins), hydrocarbon gases or nitrogen dissolved in oil and low formation temperatures will cause the structural and mechanical properties (SMP) of oil and high values of shear stress of ultimate destruction of the structure. Moreover, in conditions of low reservoir temperature (below the temperature of oil saturation with paraffin), the main factor of structure formation will be the precipitation of wax crystals [4][5]. And at higher temperatures, much higher than the temperature of oil saturation with paraffin, flow anomalies are associated with the presence of asphaltenes in the micelles, in the presence of which, even in high-temperature deposits, HVO can be noted that increasing the amount of dissolved gas for a virtually intact structure will significantly increase the viscosity of the oil.

The dependence is reversed in the case of overcoming the stresses at which the structure is destroyed [6][7] .

There are various approximate techniques determining the value of DSPG [8][9][10][11]. The DSPG values depend only on the ultimate shear stress and the permeability of the porous medium.

In studies [12][13][14], for simple models of a porous medium, equations were also derived for calculating the value of DSPG.

These formulas also take into account the porosity coefficient, the structural coefficient (takes into account the structure of the pore space). Summarizing these studies, we can conclude that today there is no precise and unambiguous definition of the value of DSPG its value is determined by many factors that 
depend on both the properties of oil and the properties of the porous medium. Due to the fact that the proportion of layers that represent a double-void system (carbonate reservoirs) has recently been increasing, studies of the presence of DSPG in such reservoirs are also of great interest. In works [15][16], studies carried out on the HVO flow in a carbonate rocks. It was revealed that in the carbonate rocks, DSPG much higher than in terrigenous. The results are also presented for different reservoir permeability: with a decrease in permeability, a sharp increase in the DSPG values is revealed. The results were explained by the fact that the formation of stronger bulk structures occurs in carbonate rocks due to the formation of more durable and thickened layers of boundary bound oil by the active components of oil at the oil-carbonate rock boundary, the thickness of which is 1.5 to 2 times greater than on a quartz substrate.

The existence of initial DSPG takes place in gas fields as well [17][18]. During gas flow in low-permeability clay reservoirs, there will also be initial DSPG. This phenomenon is primarily associated with the structure of the clay material. As is known, clay has a scaly structure, and in order to ensure gas flow to production wells, it is necessary to create pressure gradients above the initial DSPG values. When pressure gradients are applied above the DSPG, clay flakes begin to line up along the gas flow current lines, thereby ensuring its inflow to the production well [19] [20][21] .

Table 1 : The properties of the studied reservoir model

\begin{tabular}{|c|c|c|c|c|c|c|c|c|c|c|c|c|c|c|c|c|c|}
\hline 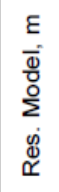 & 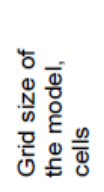 & 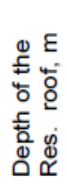 & 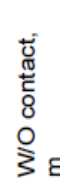 & 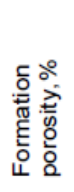 & 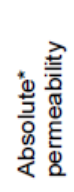 & 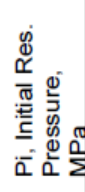 & 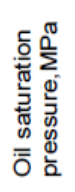 & 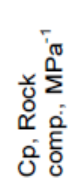 & 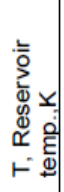 & 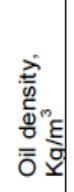 & 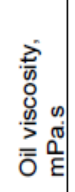 & 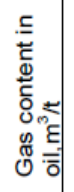 & 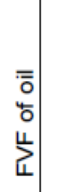 & 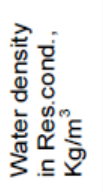 & 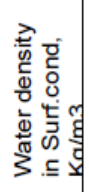 & 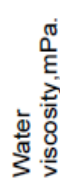 & 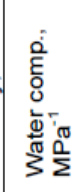 \\
\hline 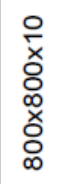 & 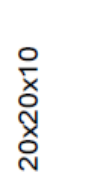 & $\stackrel{\circ}{\frac{\gamma}{\square}}$ & $\underset{\text { ָิ }}{\text { }}$ & กิ & $\begin{array}{l}\frac{0}{0} \\
\frac{\pi}{\pi} \\
\frac{\pi}{\pi} \\
>\end{array}$ & $\stackrel{\stackrel{n}{m}}{\stackrel{m}{r}}$ & $\stackrel{N}{=}$ & $\begin{array}{l}\frac{0}{x} \\
\text { n. } \\
\text { n. }\end{array}$ & $\stackrel{\circ}{\text { N }}$ & 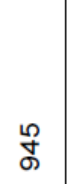 & $\frac{\stackrel{n}{\sigma}}{\sigma}$ & $\stackrel{\infty}{\leftarrow}$ & & 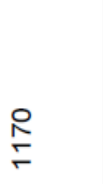 & 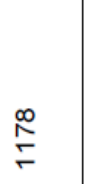 & $\stackrel{n}{=}$ & $\begin{array}{l}0 \\
\frac{1}{x} \\
m\end{array}$ \\
\hline
\end{tabular}

* Absolute permeability is a variable parameter, and the reservoir is anisotropic (vertical permeability is less than 10 times lateral).

\section{EXPERIMENTAL WORK}

The study of the influence of structural and mechanical properties (SMP) of oil on the change in the production well rate was carried out using the Tempest-More hydrodynamic modelling package version 6.7.1. The software package allows to simulate the non-Newtonian flow - flow of reservoir fluid with DSPG. The non-Newtonian flow of oil was modelled by a multiplier (factor) that changes the flow of oil (or the speed of its movement) within the specified limits of the change in the reservoir pressure gradient. Below the value of the pressure gradient $d p_{\text {limit }}$, the factor $\mathrm{F}$ has a constant value $F_{o}$ (it can be equal to zero - in the case of infinite oil viscosity). Above $\mathrm{dP}_{\text {limit }}$ and up to $\mathrm{dP}_{\text {newt }}$, the multiplier $\mathrm{F}$ changes from $\mathrm{F}_{\mathrm{o}}$ to 1 . Above $\mathrm{dP}_{\text {newt }}$, the flow of oil has a Newtonian character.

It should be noted that the method proposed by the program for modeling viscoplastic oil flow does not explicitly depend on the reservoir permeability and does not take into account the structure of the pore space, but allows only an approximate estimate of the effect of SMP on oil production and the nature of displacement. The geometric dimensions of the studied reservoir model and its properties are shown in Table 1. Note 
that a two-phase flow model (oil-water) is considered, with an initial oil saturation of 0.8. A hydrophilic reservoir with initial geological reserves of 998 thousands $\mathrm{m}^{3}$ is considered. The model considers an areal five-point development system. A horizontal production well was drilled in the center of the reservoir, the horizontal well of which is located at a depth of $1415 \mathrm{~m}$, i.e. in the middle of the formation. Four vertical injection wells are located at a distance of 50 $\mathrm{m}$ from the reservoir boundaries at each corner, penetrating the entire thickness of the reservoir. In the simulation, it was assumed that the injection and production wells are put into operation simultaneously. At the same time, the operation of production wells was limited by the bottom-hole pressure - not lower than the saturation pressure of oil with gas. For injection wells, a limitation was set on the compensation of production by injection equal to $100 \%$.

The calculations were carried out for 3 different lengths of horizontal wells: 100, 300 and $500 \mathrm{~m}$. Various options of the reservoir absolute permeability were modelled: 50 , 100, 500, 1000, 2000 and $3000 \mathrm{md}$. For each value of the permeability and length of the horizontal wellbore, 20 values of DSPG were

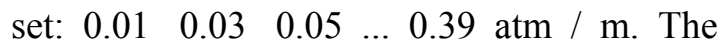
value of the pressure gradient at which the Newtonian flow was resumed was chosen according to the principle (DSPG +0.01 $\mathrm{atm} / \mathrm{m}$ ). Thus, the portion of the consistency curve at which the structure is destroyed (a sharp decrease in oil viscosity) was modelled very small.

It was important to show the situation when, in the event of a drop in reservoir pressure gradients below the value of DSPG, there would be no oil flow. Based on the results of calculations of the hydrodynamic model, the dynamics of the change in production rates was obtained, according to which the established oil production rates were determined.

\section{RESULTS AND DISCUSSION}

The article presents the most typical dependencies for horizontal wells lengths of 300 and $500 \mathrm{~m}$, reflecting the relationship between the steady-state oil production rates and permeability at different values of DSPG (Figures 1a and 2a) and the dependences of the flow rates on DSPG at various values of the reservoir's absolute permeability (Figures $1 b$ and $2 b)$.

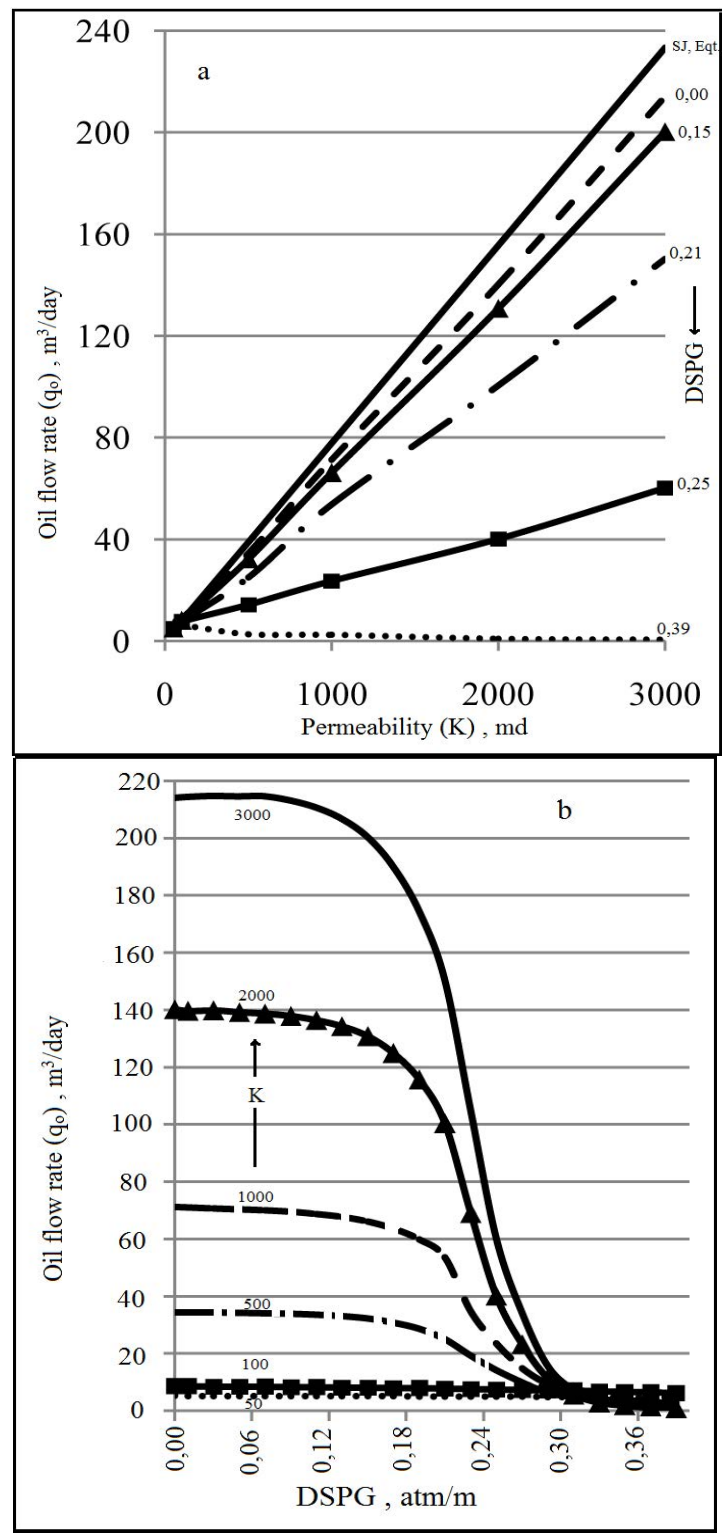

Fig. 1: Dependences of the oil flow rate of a horizontal well with a length of $300 \mathrm{~m}$ :

a) flow rate on permeability; b) flow rate on $D S P G$ 

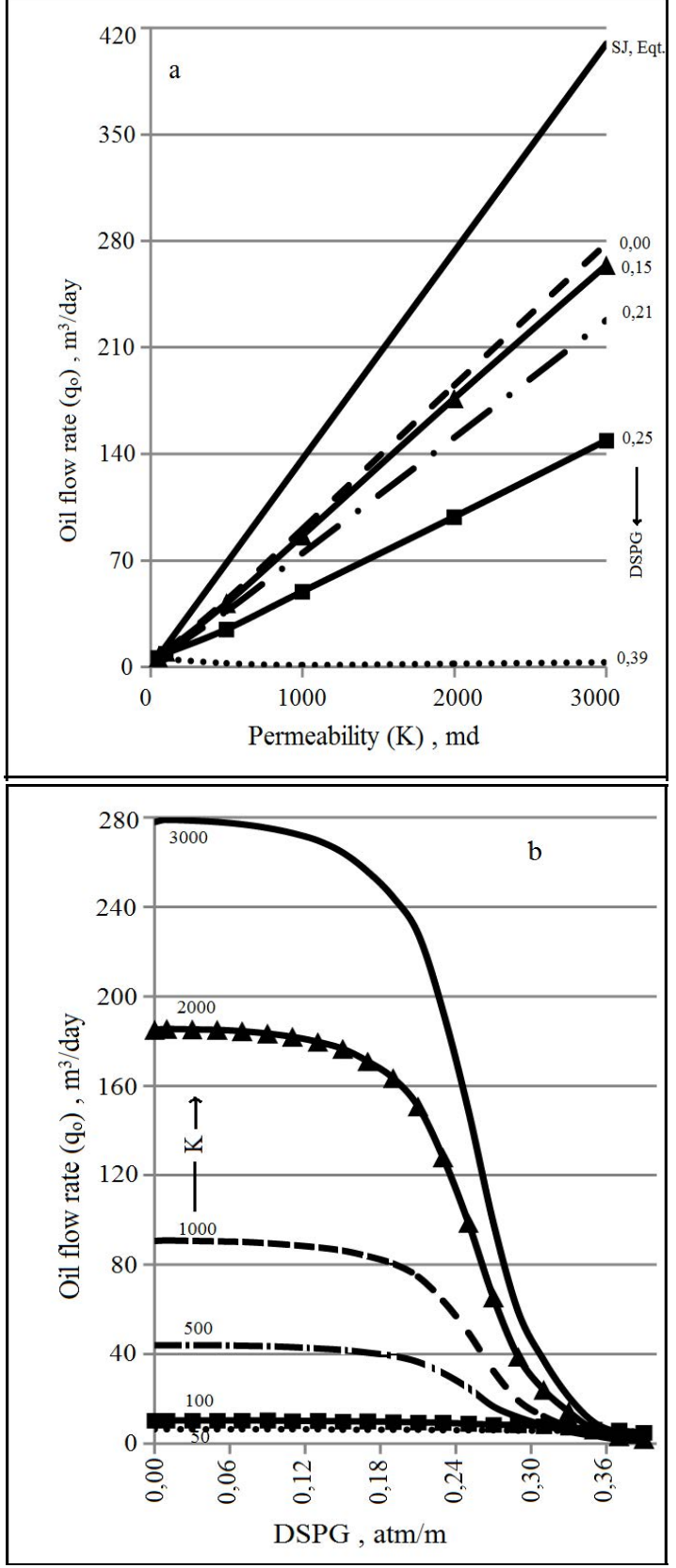

Fig. 2: Dependences of the oil flow rate of a horizontal well with a length of $500 \mathrm{~m}$ : a) flow rate on permeability; b) flow rate on $D S P G$

Analysis of the graphs shown in Figures 1 and 2 reveals the following important patterns:

- There is a significant difference between the flow rates with DSPG and the Newtonian flow regime (in the hydrodynamic model), respectively, the use of analytical formulas in the case of the development of HVO fields will lead to an incorrect forecast of production well rates.

- With an increase in the absolute permeability of the reservoir at the same value of DSPG, the difference between the flow rates of the Newtonian and nonNewtonian flows will increase significantly (Figure 1a). For example, if we consider the DSPG curve of $0.25 \mathrm{~atm} / \mathrm{m}$, we can see that at the absolute permeability of the reservoir of $500 \mathrm{md}$, the flow rates differ from the Newtonian flow (DSPG of $0.00 \mathrm{~atm} / \mathrm{m}$ ) by $12.3 \%$, and at the permeability of $3000 \mathrm{md}$ by $71.9 \%$.

- With an increase in the length of the horizontal wellbore, large pressure gradients will be created, and, accordingly, the impact of DSPG on productivity will be less. In this regard, when developing a HVO reservoir, the length of the horizontal well should be selected, taking into account the DSPG (Figures $1 \mathrm{~b}$ and $2 \mathrm{~b}$ ).

- When using any length of the horizontal wellbore, there are certain DSPG values at which the well production rates were practically the same regardless of the absolute permeability of the reservoir (Figures $1 b$ and $2 b$ ).

- An interesting anomaly is detected at large DSPG, as can be seen from the curve of $0.39 \mathrm{~atm} / \mathrm{m}$, with an increase in the reservoir permeability, the flow rate decreases inversely. This is due to the fact that at high DSPG, the drainage zone becomes much smaller. Accordingly, at high permeability, the well will start working with a high initial flow rate, and upon reaching the steady state, the flow rates will be less compared to a lowpermeability reservoir.

- Also, the task was to compare the flow rates of the hydrodynamic model according 
to the S. Joshi formula. For a horizontal well length of $300 \mathrm{~m}$, the error between production rates was minimum, for $100 \mathrm{~m}$ underestimated values of production rates, for $500 \mathrm{~m}$ - overestimated. This difference is likely due to the size of the power circuit.

To clarify the reliability of the obtained conclusions, a separate calculation was made for a model with dimensions of $1500 \times 1500$ x10 m. Reservoir and fluid properties were taken from the previous model. A development system similar to the first group of experiments (areal five-point) was chosen. It is only necessary to clarify that the injection wells are located at a greater distance from the producing horizontal well (in the first model, the distance between the producing and injection wells is $350 \mathrm{~m}$, in the second model, this distance is $700 \mathrm{~m}$ ).

Figure 3 shows similar to the previous experiment, the dependences of the flow rates of a horizontal well with a length of $300 \mathrm{~m}$ on the permeability and DSPG for a model with dimensions of $1500 \times 1500 \times 10$ $\mathrm{m}$.

Comparing two models of different sizes, we can draw the following important conclusions:

- There is a similar relationship between the S. Joshi and hydrodynamic model production rates, so it can be considered that this assumption is correct.

- In general, dependencies similar to the first considered model were obtained, with the exception of one point - a more rare location of wells led to a drop in reservoir pressure gradients. Therefore, when developing HVO fields, the correct distances between injection and production wells should be selected.

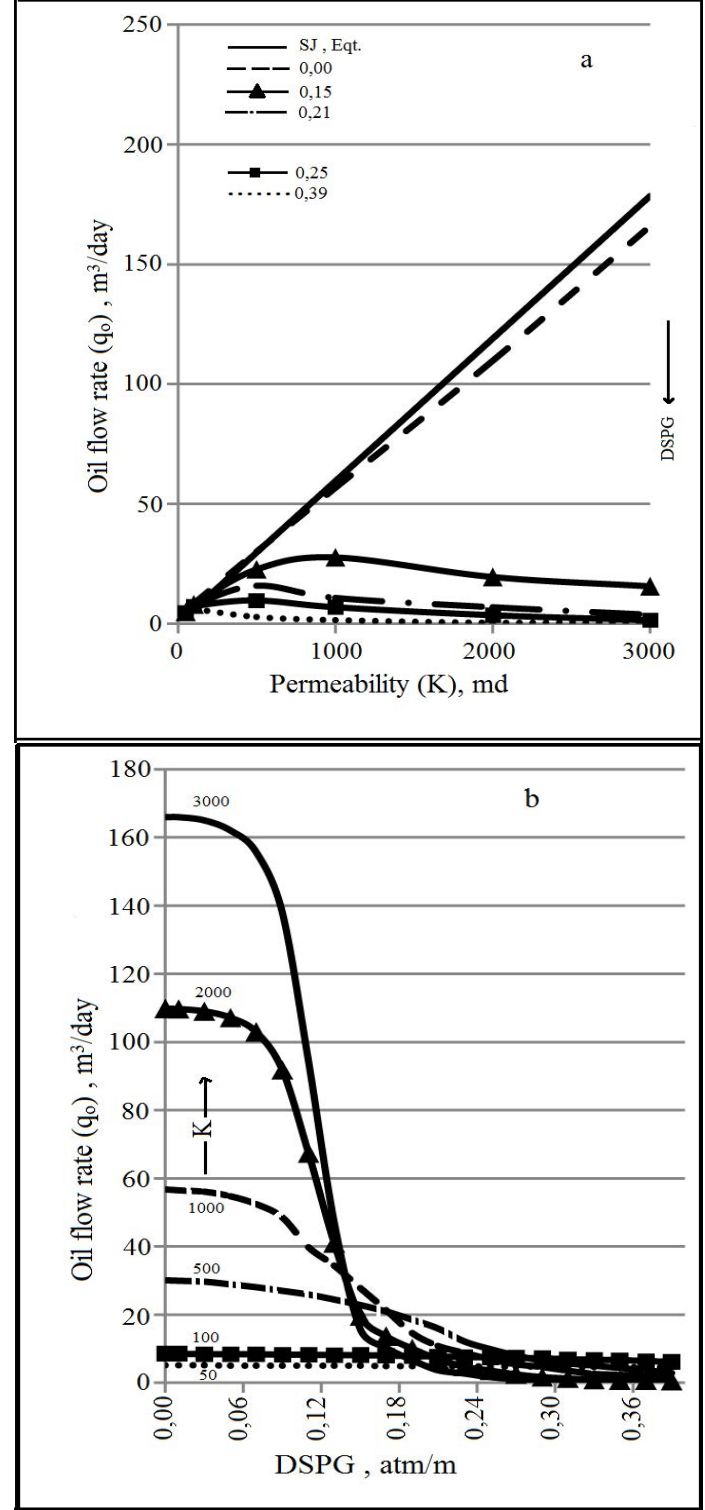

Fig. 3: Dependences of the oil flow rate of a horizontal well with a length of $300 \mathrm{~m}$ for the $1500 \times 1500 \times 10 \mathrm{~m}$ model: a) flow rate on permeability; b) flow rate on DSPG

\section{CONCLUSIONS}

Thus, it has been established that the influence of the non-Newtonian mode of the HVO flow in a porous medium is significant in determining the technological indicators of the development of production wells. 
Failure to take into account the structural and mechanical properties of oil will lead to an incorrect forecast of well flow rates and to mistakes, as well, in the design of systems for the development of $\mathrm{HVO}$ deposits.

It is also necessary to understand that failure to take into account the structural and mechanical properties of oil will lead to an incorrect determination of not only flow rates, but also oil recovery factors (RF).

\section{REFERENCES}

1. Bocharov V.A. (2000).Development of oil reservoirs in conditions for the manifestation of the initial pressure gradient. Moscow: VNIIOENG, 252.

2. Al-Obaidi, Sudad H.(1996). "Разработка Методики И Технологии Обработки Данных ГИС И Керна Для Определения Подсчетных Параметров Нефтегазовых Месторождений Ирака : На Прим. Месторождения Вост. Багдад." OSF Preprints, 10.31219/osf.io/f6vka .

3. Devlikamov, V.V. and Khabibullin A. (1969). Structural formation oil viscosity // Proceedings of the Ufa Oil institute. Moscow: Nedra, No. 5,81-86.

4. Al-Obaidi, Sudad H. and Guliaeva NI. (2002). "Determination of Flow and Volumetric Properties of Core Samples Using Laboratory NMR Relaxometry." engrXiv, 10.31224/osf.io/t46wj .

5. Abbasov, A.A.et al. (1976). Influence of temperature, pressure and dissolved gas on the structural and mechanical properties of oil. Works of Azineftekhim (Baku), No. 26, $19-24$.

6. Al-Obaidi, Sudad H. and Аль Обейди, Судад Х. (1996).“ Определение ГлиниСтости Продуктивных Пластов Месторождений Нефти И Газа Восточного Багдада." OSF Preprints, 10.31219/osf.io/dmw9c .
7. Pearsonand, JR and Tardy, PM (2002). Non-Newt. Fluid Mech.102,447.

8. Al-Obaidi, Sudad H.(1990)"Comparison of Different Logging Techniques for Porosity Determination to Evaluate Water Saturation."engrXiv, 10.31224/osf.io/fvj9u.

9. Savins, J.G.( 1969). NONNEWTONIAN FLOW THROUGH POROUS MEDIA Ind. Eng. Chem. 61, 10, $18-47$.

10. Al-Obaidi, Sudad H.(1998). "Areas of Effective Application of Submersible Centrifugal Pump Installations with and Without a Gas Separator." engrXiv, 10.31224 osf.io/2c $84 h$.

11. Odeh, A.S. (1979). Flow of NonNewtonian Power-Law Fluids Through Porous Media.SPEJ,19(03), https:// doi.org/10.2118/7150-PA.

12. Al-Obaidi, Sudad H.(1999) "Submersible Screw Pumps in Oil Industry."engrXiv, 10.31224/ osf.io/zqu3c .

13. Alexandrou, A.N. et al. (2001). Inertial, viscous and yield stress effects in bingham fluid filling of a 2-d cavity, Journal of nonnewtonian fluid mechanics, vol.96, issue.3, 383-403.

14. Al-Obaidi, Sudad H., Patkin AA, and Guliaeva NI. 2020. "Advance Use for the NMR Relaxometry to Investigate Reservoir Rocks.” OSF Preprints,10.31219/osf.io/jmb9t .

15. Gafarov Sh.A. et al. (2005). Flow features of non-Newtonian oils in porous carbonate media // Oil industry. No. 11,52 -54 .

16. Al-Obaidi, Sudad H. (1996). "Рaзpaботка Методики И Технологии Обработки Данных ГИС." OSF Preprints, 10.31219/ osf.io/e68us . 
17. Barnes, H.A.(1999). The yield stress -A review, J. Non-Newt. Fluid Mech, vol.81, 133-178.

18. Al-Obaidi, Sudad H. (1996). “ Модиф икация Уравнения Арчи Для Определения Водонасыщенности Нефтяного Месторождения Восточный Багдад." OSF Preprints, 10.31219/ osf.io/ tqpn5 .

19. Al-Obaidi, Sudad H., and Galkin AP. 2005. "Dependences of Reservoir Oil Properties on Surface Oil." OSF Preprints, doi:10.31219/osf.io/789wp .

20. Barnes, H.A. et al. (1989). An Introduction to Rheology.

21. Al-Obaidi, Sudad H. 2004. "Modified Use of Microbial Technology as an Effective Enhanced Oil Recovery." OSF Preprints, doi:10.31219/osf.io/xgthz .

\section{Cite this Article}

Al-Obaidi SH , Galkin AP , Patkin AA. Prospects of High Viscosity Oil Flow Rate In Horizontal Wells. 2006; 5(4): 56-62p. 